\title{
Measuring Class Hierarchies in Postindustrial Societies: A criterion and construct validation of EGP and ESEC across 31 countries
}

Oscar Smallenbroek

Sciences Po, Paris, France

Florian Hertel

University Hamburg, Hamburg, Germany

Carlo Barone

OSC, Sciences Po, Paris, France 


\section{Introduction}

Four decades ago, Erikson, Goldthorpe and Portocarero (1979) published a comparative analysis of social mobility using a class schema that would become known as EGP. This schema had an immense influence: it became the paradigmatic approach to class analysis in sociological research. A review of empirical papers published between 2015 and 2019 in top sociology journals shows that $78 \%$ of those investigating social class differentials used EGP or an update of this schema, known as $\operatorname{ESEC}^{1}$ (Barone, Hertel and Smallenbroek 2020). EGP-like schemes are widely used in social stratification research on social mobility, educational and labor market inequalities and their application also extends to other research domains, such as studies on values, lifestyles, attitudes and class voting (Manza, Hout and Brooks 1995; Rose and Harrison 2010; de Regt, Smits and Mortelmans 2012; Kulin and Svallfors 2013). Hence, EGP-like measures represent the paradigmatic measurement of social class in sociological research.

However, EGP-like measures did not remain unchallenged. Several researchers have repeatedly criticized that they fail to capture the core class divides of post-industrial occupational structures driven by educational expansion, occupational upgrading or polarization as well as increasing female labor force participation (Esping-Andersen 1993; Oesch 2006; Güveli and Graaf 2007; Weeden et al. 2007; Hertel 2017). This criticism has only rarely been addressed in previous validation studies (Williams 2016). In this article, we assess the criterion and construct validity of EGP and ESEC, making three main contributions.

First, we assess the homogeneity of the salariat class, the category that groups all managerial and professional occupations together into an undifferentiated upper class. Indeed, critics maintain that

1 Every EGP class has an equivalent ESEC category, and their empirical distributions, displayed in figure 1, are very similar. However, ESEC has more systematic and better-documented procedures to operationalize the class schema from a variety of occupational data. Studies based on British data sometimes used also another variant of EGP, known as NS-SEC, which provided the starting point to build ESEC. In the text we denote EGP and its variants as 'EGP-like' schemes. 
EGP-like schemes have poor discriminant power to pinpoint privileged positions, especially in postindustrial class structures (Güveli, Need, and De Graaf 2007). Figure 1 substantiates this criticism by presenting the distributions of EGP and ESEC in 31 European countries in 2010 and 2015, based on data from the European Working Conditions Survey (Eurofound 2017). As can be seen, the higher and lower salariat classes collectively account for $34 \%$ to $49 \%$ of employed respondents in western continental Europe, the UK, Scandinavia and Baltic countries. In Southern Europe and some Eastern European countries these values are lower, but the salariat classes still comprise between one quarter and one third of the employed. The distribution for ESEC is very similar, confirming that about four out of ten workers are assigned to the upper class in several rich countries. Incorporating top-level managers, high school teachers, lawyers, journalists and artists as it does, this large and heterogeneous upper class is a major source of concern for the analysis of social inequalities. When such a large share of employees is assigned to 'privileged' positions, it is doubtful that occupational advantage is measured with sufficient precision. This is even more problematic in the context of research indicating that the worldwide growth of income inequality is driven by the increasing concentration of resources in top-level occupations (Piketty, Saez and Zucman 2018). Problems at the top of the class hierarchy correspond to similar heterogeneity at the bottom. As figure 1 shows, the working classes comprise roughly $30 \%$ to $40 \%$ of employees in each country. Again, EGP-like schemes assume no vertical distinction within this large group, for instance between skilled and unskilled blue-collar workers. 
Figure 1: Class distributions in 31 European countries according to the ESEC and EGP schemes

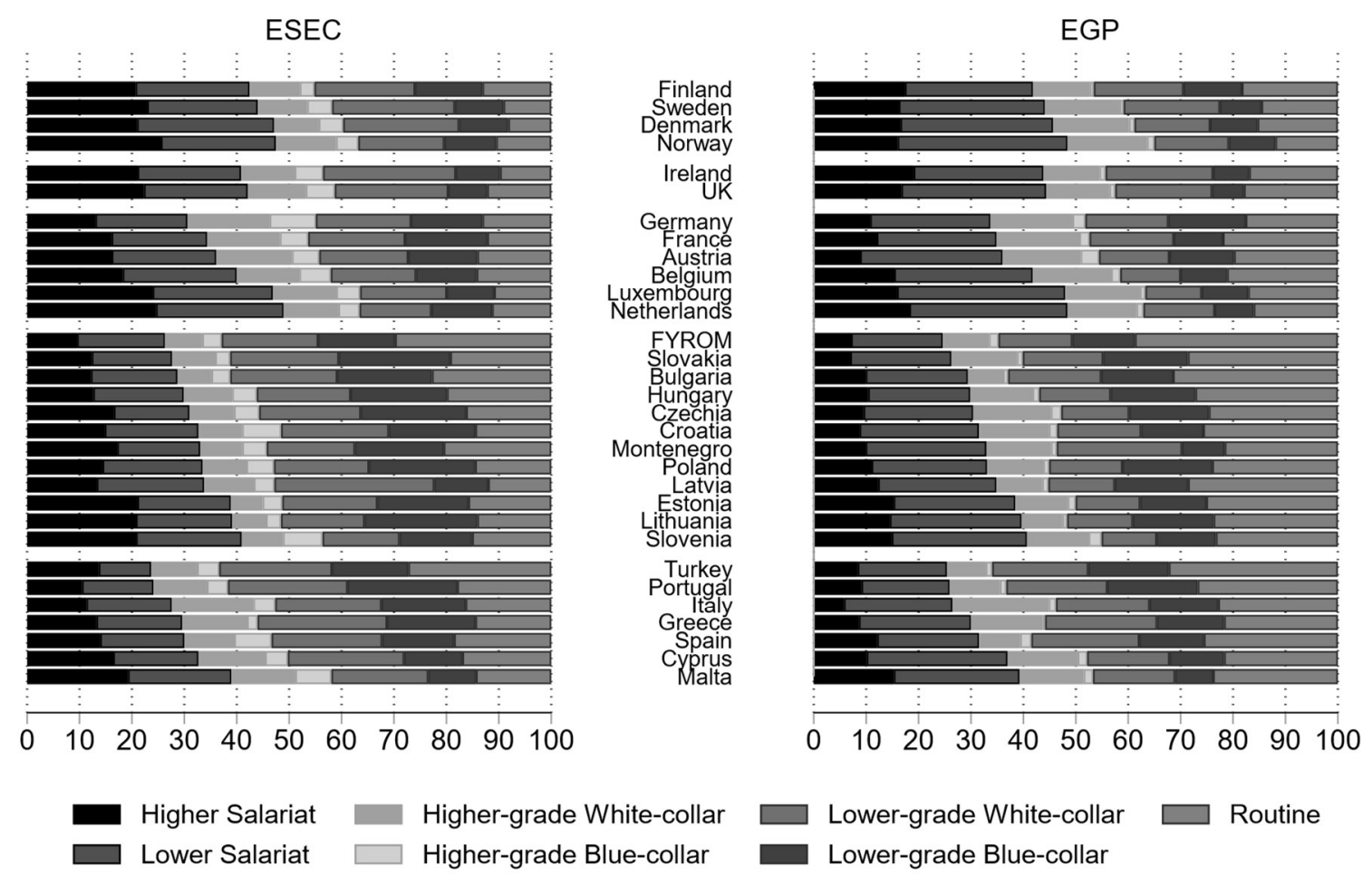

Note: EWCS 2010, 2015. Weighted distributions. Sample size: 63,877 
Unsurprisingly, several critics of EGP have proposed to introduce more fine-grained distinctions within the salariat classes, typically by differentiating between managerial and professional occupations, or within the working classes (Oesch 2006; Hertel 2017). However, the empirical evidence supporting these claims is based on external criteria, such as income, mobility patterns or political preferences. These external criteria are relevant to assess the heuristic value of these class schemes, but advocates of EGP-like schemes have rightfully replied that they were not primarily designed to measure these outcomes (Evans and Mills 1999; Rose and Harrison 2010). Instead, EGP-like schemes specify employment relations as their core theoretical construct (Goldthorpe 2007). Therefore, their validity as well as the relevance of additional distinctions should be assessed against this yardstick.

Following the classical distinction in validation research, we study both the criterion and construct validity of the EGP and ESEC schemes (Cronbach and Meehl 1955). Following Borsboom, Mellenbergh and van Heerden (2004), criterion validity refers to the correspondence between class categories and the underlying theoretical construct of employment relations which, according to Goldthorpe's (2007) class theory, involves the two dimensions of the time horizon and reward types of contractual arrangements. Construct validity refers instead to the association between class and external criteria measuring different dimensions of occupational advantage (Markus and Lin 2012). In particular, we select income, socio-economic status, work autonomy and contract type.

Our second contribution involves the supposed gender-neutrality of EGP-like schemes. ${ }^{2}$ EGP was built to analyze social mobility among men in industrial societies. Some critics argue that the increasing labor market participation of women and the expansion of female-dominated service occupations resulted in new class cleavages that EGP is unable to map (Esping-Andersen 1993; Oesch 2006). More fundamentally, it is unclear whether EGP-like schemes measure employment relations equally well for men and women and whether the advantages and disadvantages afforded by social class (e.g., income,

\footnotetext{
${ }^{2}$ This issue should not be confused with the question of whether the family or the individual is the correct unit of analysis, and whose class position should be taken as proxy for the family's social class in stratification research (Erikson, Goldthorpe 1992; Beller 2009).
} 
work autonomy) are gender-neutral. Our criterion and construct validation exercise provides evidence on this under-researched issue, which is fundamental to establishing whether EGP-like schemes can be applied to both genders.

Our third contribution involves the validity of EGP and ESEC for comparative research. EGP was devised to facilitate cross-country analyses of social mobility and its success is inextricably tied to the growth of comparative studies in social stratification research. These studies implicitly assume that EGP and ESEC measure employment relations equally well across countries and that class-related hierarchies, defined for instance in terms of income or social status, are largely invariant, at least among market societies (Erikson et al. 1979; Erikson and Goldthorpe 1985; Erikson and Goldthorpe 1992). This assumption is indeed required to interpret country differences or similarities in a substantive manner, rather than as mere measurement artefacts. Our validation exercise covers 31 countries that differ markedly in terms of economic development, occupational structures and institutional arrangements. In the next section, we provide a concise description of the theoretical rationale of EGP and ESEC in order to articulate the underlying constructs that we measure. In the third section, we systematically review previous validation studies in relation to the aforementioned research gaps. The fourth section describes the data, variables and methods for the validation analyses. Section five reports the criterion validation results for each of the above three issues, while section six reports the results of the construct validation analyses. Section 7 concludes with a discussion of our findings and their implications for the use of EGP-like schemes in sociological research. 


\section{The theoretical framework of EGP-like schemes: social class and employment relations}

This section presents the social class categories of EGP and ESEC, the theoretical constructs that they are supposed to measure and the explanatory mechanisms postulated by Goldthorpe's (2007) theory. Figure 2 presents a graphical summary of these elements. On the right panel, we find the class categories, ranked into a three-level hierarchy (Erikson and Goldthorpe 1992; Goldthorpe 2007; Rose and Harrison 2010). The higher and the lower salariat (classes I and II in EGP), predominantly comprising managerial and professional occupations, constitute the top of the class hierarchy ${ }^{3}$. The intermediate classes comprise higher-grade white-collar employees (IIla), higher-grade blue-collar employees (mainly technicians and manual supervisors, V), and independent workers in craft, trade and agriculture. Finally, lower-grade white-collar workers (mainly sales and service occupations, Illb), lower-grade blue-collar workers (VI) and routine workers (VIlab) are placed at the bottom of the class hierarchy. We refer to these three levels as upper, intermediate and working classes. Importantly, no hierarchy is assumed within each level, for instance between the higher and the lower salariat (Erikson and Goldthorpe 1992; Goldthorpe 2007; Rose and Harrison 2010).

\footnotetext{
${ }^{3}$ To avoid confusion, throughout this article we name social classes following the ESEC terminology. We use the EGP roman numbers to illustrate the correspondence with EGP classes.
} 
Figure 2: Goldthorpe's conceptual framework and class hierarchy

Explanatory Mechanisms

\begin{tabular}{|c|c|c|c|c|}
\hline $\begin{array}{c}\text { Asset } \\
\text { Specificity }\end{array}$ & $\begin{array}{c}\text { Monitoring } \\
\text { Difficulty }\end{array}$ & $\begin{array}{c}\text { Contract } \\
\text { Type }\end{array}$ & $\begin{array}{c}\text { Time } \\
\text { Horizons }\end{array}$ & $\begin{array}{c}\text { Reward } \\
\text { Type }\end{array}$ \\
\hline High & High & $\begin{array}{l}\text { Service } \\
\text { Contract }\end{array}$ & $\begin{array}{l}\text { Long- } \\
\text { term }\end{array}$ & Diffuse \\
\hline High & Low & Mixed & $\begin{array}{l}\text { Short- } \\
\text { term }\end{array}$ & Diffuse \\
\hline Low & High & Contract & $\begin{array}{l}\text { Long- } \\
\text { term }\end{array}$ & Specific \\
\hline Low & Low & $\begin{array}{c}\text { Labor } \\
\text { Contract }\end{array}$ & $\begin{array}{l}\text { Short- } \\
\text { term }\end{array}$ & Specific \\
\hline
\end{tabular}

Class Hierarchy

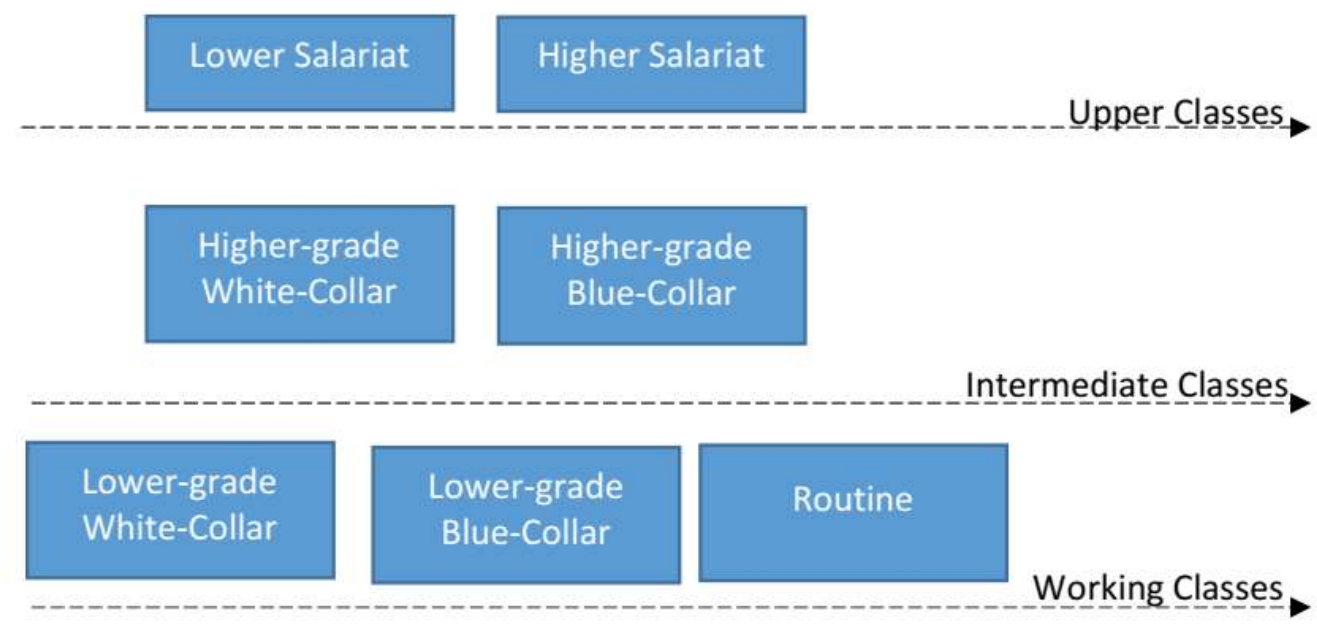


The first criterion of class allocation in EGP-like schemes refers to the possession of the means of production (Erikson and Goldthorpe 1992). This criterion differentiates between employers, who buy the labor of others, employees who sell their labor, and independent workers, who do not buy or sell labor $^{4}$. With employees accounting for about nine tenths of the active labor force in western countries, further distinctions within dependent employment are required (Rose and Harrison 2010). These distinctions are theoretically justified on the basis of differences between occupations in their typical employment relations, i.e., the formal and informal contractual arrangements between employees and their employers. Goldthorpe (2007) conceives of employment relations as the conceptual heart of social classes. They constitute the solution to the principal-agent problem that employers face when attempting to extract effort from employees in a free market exchange. Buying command over employees' time, however, only ensures partial control over their effort and always leaves employees the possibility of shirking. Opportunities for shirking are not equally distributed across occupations. They depend on two key characteristics of occupations: the difficulty of monitoring their work tasks and their asset specificity. These two characteristics are the explanatory mechanisms driving systematic variations between classes in the two core dimensions of employment relations, namely the time horizon (long-term vs. short-term) and the type of rewards (diffuse vs. specific) involved in contractual arrangements. The left panel of figure 2 illustrates the relationship between latent explanatory mechanisms, dimensions of employment relations and social class categories.

Managerial and professional occupations in the salariat classes present severe monitoring problems, as it is difficult (and costly) to scrutinize the quality of performance. Rather than trying to measure and reward productivity in detail, employers therefore set a system of diffuse rewards, involving for instance bonuses related to the performance of the firm or of their work teams, as well as fringe benefits. High monitoring problems create incentives for diffuse rewards to motivate workers to

\footnotetext{
${ }^{4}$ Large employers are usually differentiated from independent workers because they have at least 10 employees. The former are assigned to the higher salariat, while the latter constitute the intermediate self-employed class. For a discussion of this point, see Erikson and Goldthorpe (1992) and Rose and Harrison (2010). Following previous validation studies, we study employees and the corresponding differences in employment relations.
} 
provide consistently high-quality performance. Moreover, these occupations display high asset specificity, that is, their execution involves large amounts of job- and organization-specific skills. Since managers and professionals are difficult to replace, employers seek to foster a long-term commitment to the firm that motivates them to develop these skills. Consequently, employers offer prospective, long-term incentives, such as occupational security or career development prospects. At the opposite extreme, unskilled, routine occupations are easy to monitor and involve low asset specificity. Therefore, employment relations in these occupations involve a shorter time horizon and more specific forms of compensation (e.g., piecewise or timewise). Within the intermediate classes, higher-grade white-collar jobs involve low asset specificity but moderately high monitoring problems, and are thus regulated via a mixed type of contract, characterized by diffuse but short-term rewards. Conversely, higher-grade blue-collar occupations display high asset specificity but low monitoring problems, and are thus regulated via a qualitatively different type of mixed-form contract, displaying long-term but specific types of rewards.

Hence, the two explanatory mechanisms (asset specificity and monitoring problems) drive variations in the two dimensions of employment relations, resulting in the three-level hierarchy of EGP and ESEC displayed in figure 2. Employment relations in upper class occupations are regulated via a service contract involving long-term incentives and diffuse rewards. The working classes are offered a labor contract scoring low on both dimensions, whereas the intermediate classes display mixed contractual arrangements (Rose and Harrison 2010).

\section{Review of criterion and construct validation studies}

\subsection{Criterion validation studies}

The theoretical framework of employment relations underpins the empirical procedures to build EGPlike schemes. First, information on employment status and the number of employees for the selfemployed is used to differentiate employers, independent workers and employees (cf. footnote 4). 
Then the latter are further differentiated on the basis of their ISCO titles and supervisory status, as displayed in figure 3. The algorithms to build EGP-like schemes thus do not directly rely on indicators of employment relations, which are seldom available in survey data. Instead, they group together occupations into the same class category based on their supposed similarity in terms of employment relations. These assignments involve a significant degree of subjective judgement and guesswork (Mitnik and Cumberworth 2018; Rose and Harrison 2010:25). This issue motivated scholars to carry out some criterion validation studies to assess the correspondence between class categories and the supposed patterns of employment relations, using survey data containing both the information to build EGP-like schemes and indicators of the two dimensions of employment relations. In figure 3 we display the most common indicators used to measure the time horizon and reward types of employment contracts. 


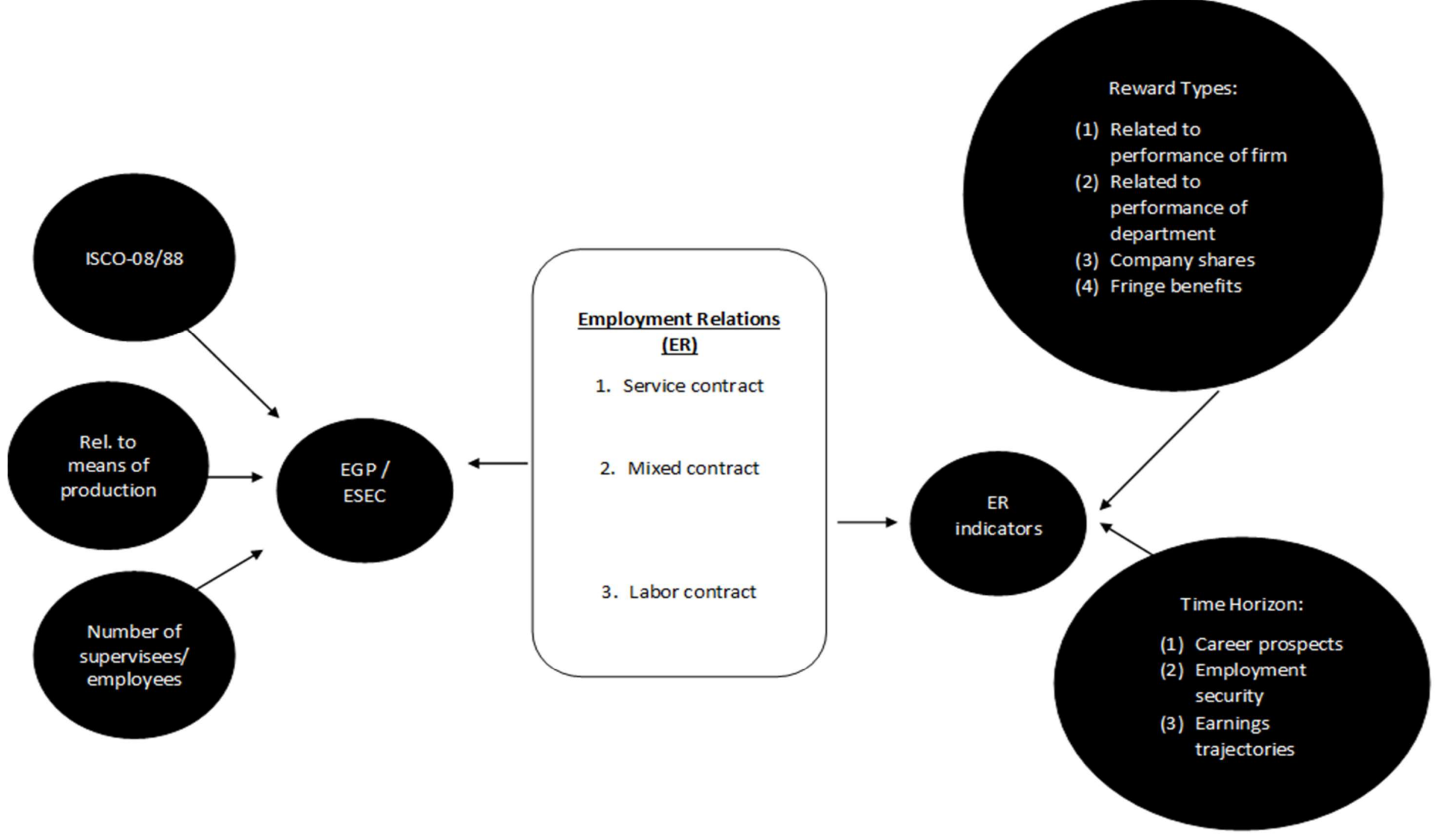


We identified 17 articles assessing the criterion validity of EGP and ESEC using indicators of employment relations, such as items on internal promotion prospects and pay increase schemes (time horizon dimension), or on payment methods and access to special bonuses and fringe benefits (type of rewards). We report detailed information on these 17 articles in Appendix $\mathrm{N}$. These indicators (or some synthetic scores) are typically regressed on social class. Alternatively, a latent class approach identifies a typology of employment relations, which are then cross-tabulated with the class scheme under study. Overall, the broad patterns of results of these criterion validation studies support the underlying theory, that is, employment relations in the upper classes are closer to the service contract type, while those in the working classes are closer to the labor contract type.

At the same time, deviations from the theory are far from negligible. Evans and Mills (2000) report that one third of the higher salariat class (EGP I) did not have a service contract and that mixed-form contracts were more common than service contracts in the lower salariat (II). Two other studies suggest that the boundaries between higher-grade white-collars (IIla) and professions in the lower salariat (II) may be weaker than EGP would suggest (Evans and Mills 1998; McGovern et al. 2007). Service class contracts also do not seem be the exclusive privilege of the salariat: Zou (2015) found that in China a service contract is the rule rather than the exception among supervisors in higher-grade blue-collar positions (V). Evans and Mills (1998) reported a similar problem in UK, noting that the only difference between higher-grade blue-collar (V) and managers in the lower salariat (II) relates to the number of supervised employees. Interestingly, some of these studies suggest that the lower salariat (II) may be more heterogeneous than supposed. Professionals in the lower salariat (II) bear more resemblance to higher-grade white-collar positions (IIla), while managers in the lower salariat (II) are akin to supervisors in higher-grade blue-collar positions (V). However, a key feature of EGP-like schemes is precisely the aggregation of managerial and professional occupations based on the assumption that they share comparable employment relations. Previous criterion validation studies have not assessed this assumption (but see McGovern et al. 2007), despite the criticism mentioned in section 1 that the upper class of EGP-like schemes is too large and heterogeneous. 
Fewer problems are reported with regard to differences between the intermediate and working classes. Several studies find systematic differences between the employment contracts of higher-grade (IIla) and lower-grade (IIIb) white-collar classes (Evans 1992; 1996; Evans and Mills 1998; McKnight and Elias 2003; McGovern et al. 2007; Bihagen, Nermo and Erikson 2010; Brousse, Monso and Wolff 2010; Wirth et al. 2010; Zou 2015; Williams 2016), thus corroborating this differentiation suggested by Erikson and Goldthorpe (1992) for the analysis of women's social mobility. The ESEC schema institutionalized this division by demoting lower-grade white-collar occupations to a labor contract. Unfortunately, only two out of the 17 validation studies conducted separate analyses for men and women, and they reported mixed results (Birkelund, Goodman and Rose 1996; Evans 1996). Hence, it remains unclear whether EGP-like schemes measure the employment relations of men and women equally well, even though this is a critical assumption when comparing class attainment across genders. An additional limitation of existing research is that only two validation studies involve more than one country ( Evans and Mills 1999; Bihagen et al. 2010). Moreover, taking all country case studies together allows little generalization: 11 of the 17 studies involved the UK ${ }^{5}$. This is a major limitation since EGP and ESEC have been extensively used in comparative research, thus implicitly assuming that the relationship between social class and employment relations is cross-nationally invariant.

Furthermore, only three criterion validation studies out of 17 studies focused on ESEC (Brousse et al. 2010; Wirth et al. 2010; Katrňák 2012), whereas the remaining articles tested only the validity of EGP (or its British adaptation, known as NS-SEC). ESEC was introduced one decade ago as an improved version of EGP (see footnote 1) that would replace its predecessor (Rose and Harrison 2010). Even according to Erikson and Goldthorpe themselves ESEC should supersede EGP (personal communication). However, EGP continues to prevail in current stratification research (Barone et al.

\footnotetext{
${ }^{5}$ This is probably due to the availability of high-quality data for this country and to the large number of contributions of two British scholars, J. Evans and C. Mills, who co-authored about half of the criterion validation studies.
} 
2020). In the absence of validation studies contrasting the two schemes other than the volume that introduced ESEC (Rose and Harrison 2010), there is little justification for either choice.

Finally, due to data constraints, several previous studies conflate indicators of employment relations (time horizon and reward types) with indicators of the underlying explanatory mechanisms (asset specificity and monitoring problems). If the research question is whether EGP and ESEC measure what they purport to measure (criterion validity), then the critical issue is the association between class and employment relations. This association could be explained by the two supposed mechanisms, or by other mechanisms, such as productivity-based differences between occupations (Tåhlin 2007; Williams 2016). It should be noted that the formulation of the explanatory mechanisms arrived late (Goldthorpe 2007) and, even if Goldthorpe's explanation is wrong, EGP and ESEC could still correctly measure employment relations. Unfortunately, only four of the previous 17 studies preserve the distinction between measures of employment relations and of the underlying mechanisms (see appendix N). This paper complements earlier research by carrying out the first large-scale, comparative criterion validation analysis, assessing the validity of both schemes separately for men and women, and across multiple operationalizations that are common in empirical research. In line with the underlying conceptual framework, we differentiate between the two dimensions of employment contracts but ignore the separate analysis of the explanatory mechanisms.

\subsection{Construct validation studies}

Class theory predicts social class differences in life chances, for instance in terms of systematic earnings differentials or with regard to unemployment risks. Construct validation studies of EGP and ESEC have therefore assessed the extent to which these schemes are associated with these outcomes and whether the association pattern is consistent with theoretically derived hypotheses (Rose, Pevalin and O'Reilly 2005). Additionally, these indicators of life chances provide a benchmark to assess class hierarchies, since higher classes should score more favorably on them. 
The volume on ESEC edited by Rose and Harrison (2010) contains the most extensive construct validation analysis of EGP and ESEC, assessing their predictive power with regard to a variety of external outcomes, such as wages, unemployment and poverty risks and health indicators. The broad patterns of class differentials are consistent with the theory for both ESEC and EGP, with the latter performing marginally better for most outcomes. Similar results are also presented by Goldthorpe and McKnight (2006) who study the association of class (NS-SEC variant) and selected economic characteristics to demonstrate vertical class differences. Unemployment risks differ in particular between blue-collar and white-collar classes; long-term unemployment experience differentiates the higher salariat with the lowest risks from the lower salariat and intermediate classes in the middle, and from the working classes, which experience the highest risks (Gallie et al. 1998). A similar pattern is observable with regard to class-specific earnings-age profiles. With regard to class-specific wage growth differences between men and women, Bihagen (2008) reports little differences for Sweden. However, he also finds quite strong differences in wage growth between the higher and lower salariat with the latter rather resembling the intermediate and working classes.

The studies presented in Rose and Harrison (2010) also examine the relation between social class and indicators of asset-specificity and monitoring problems. For both EGP and ESEC, the higher salariat class (or EGP I) display higher values than the lower salariat (II) on both dimensions for men and for women. Moreover, lower-grade white-collar and blue-collar occupations (IIIb and VI) display higher values than routine occupations (VII). Similar patterns are detected for wage differentials and poverty risks. Four additional studies assess class differences in work autonomy, taken as an indicator of monitoring problems and three of them report that it is higher for the higher salariat than for the lower salariat (McGovern et al. 2007; Wirth et al. 2010; Evans 1996; Wiliams 2016;). Two studies also confirm the existence of significant wage differences between the two salariat classes (Evans 1992; 1996).

Overall, the criterion and construct validity studies lend considerable credibility to EGP-like schemes while also suggesting that class boundaries are blurrier than the theory predicts. Gender and cross- 
national differences, however, are clearly under-researched and there is virtually no evidence to suggest that the employment relations of higher and lower managers and professionals are sufficiently homogeneous to warrant their aggregation into a unified upper class.

\section{Data, variables, and methods}

\subsection{Data and variables}

The European Working Conditions Survey (EWCS) is a repeated, cross-national survey run every 5 years since 1990 by Eurofound in collaboration with the national agencies of participating countries (Eurofound 2017). Its target population comprises workers aged 15 or older, selected via multi-stage, stratified sampling and interviewed face-to-face. The average response rate was $59.6 \%$ in 2010 and 67.6\% in 2015 (Gallup Europe 2010; IPSOS 2015). Data collection is harmonized across countries by an independent market research company which also provides design and post-stratification weights. Sampling weights account for different selection probabilities of primary sampling units, while poststratification weights reflect actual population size and the socio-demographic structure of the country ${ }^{6}$. The EWCS provides high-quality data of at least 1,000 cases per country-wave which are representative of employed and self-employed individuals. We use data from 2010 and 2015 as only these waves include ISCO information at the 3-digit level required for class assignment. We study data from 31 of the 36 countries in the ECWS. Romania and Kosovo are dropped from the analyses due to a high percentage of missing data, while Albania, Switzerland, and Serbia are dropped owing to small sample size, partly as a result of appearing in only one wave.

\footnotetext{
${ }^{6}$ Sampling weights are the inverse of the product of the selection probabilities at each stage of the sampling design. Post-stratification weights adjust for non-response to ensure that the sample accurately reflects the socio-demographic structure of the target population, using intercellular and marginal weighting on a countryby-country basis (Gallup Europe 2010).
} 
After country selection, the EWCS data consists of 80,527 respondents. We restrict the age range (1865 ) and, following standard practice in criterion validation studies of class schemes we also exclude all self-employed from the analysis, as they do not report data on their employment relations. We exclude respondents who work less than 5 hours per week, and those in education, apprenticeships, or training. We retain respondents who are unemployed, retired, on parental leave or doing household labor if they had a previous job, since they answered questions on employment relations with reference to their last job. From the 64,325 respondents left, we retain an analytic sample of 61,993 individuals after deletion due to missing data. More information on the EWCS design, missing data and missing data analysis can be found in Appendix A and C.

We construct EGP and ESEC using 3-digit ISCO codes of occupational titles, a dummy for selfemployment and the number of supervisees to promote certain ISCO codes to the salariat or highergrade blue-collar classes. For EGP we employ ISCO-88 codes and the algorithm developed by Ganzeboom and Treiman (1996). For ESEC we use the routine for ISCO-08 codes proposed by Harrison and Rose (2005) and implemented in the 'iscogen' Stata package (Jann 2019)'. The question on supervision that we use to identify supervisors is quite restrictive ("How many people work under your supervision, for whom pay increases, bonuses or promotion depend directly on you?") and thus allows us to capture managerial professions with enough precision (Pollack et al. 2010).

We test four different versions of EGP and ESEC. In the first version, the two salariat classes are distinguished as in the original classifications (Erikson et al. 1979). The second one merges them together, following common practice in comparative stratification research (Erikson and Goldthorpe 1992). The next two versions introduce a distinction between managers and professionals within the salariat class (Oesch 2006; Güveli et al. 2007). The third version merges higher and lower salariat, but distinguishes between managers and professionals (Esping-Andersen 1993; Hertel 2017). The fourth

\footnotetext{
${ }^{7}$ We also created ESEC based on ISCO-88 codes using the crosswalk from ISCO-88 to ISCO-88 (com) into ESEC provided by Wirth and Fischer (2008), allowing us to compare results for ESEC across occupational coding schemes ISCO-88 and ISCO-08.
} 
version combines the distinction between higher and lower salariat with the distinction between managers and professionals, thus resulting in four salariat classes. ${ }^{8}$ Higher Managers are respondents in the higher salariat (higher service class for EGP) with major group ISCO 1 occupation (managerial occupations) or with supervisory duties; high professionals comprise the remaining incumbents of the higher salariat. We follow the same logic to differentiate lower managers from lower professionals ${ }^{9}$.

For the criterion validation analyses, we select various indicators for the two dimensions of employment relations. The time horizon dimension is measured with three items. Respondents were asked to state their agreement with two statements about their occupation (ranging from 1 "strongly agree" to 5 "strongly disagree"): "I might lose my job in the next 6 months" and "My job offers good prospects for career advancement". A third item asks whether respondents' salary has "decreased", "not changed" or "increased" within the last 12 months. The career advancement item is reverse coded so that higher scores indicate a longer time horizon. About $89 \%$ of the analytical sample has valid answers for all these items, while $9 \%$ has one missing response. Missing data likely reflect occupational uncertainty and ceiling effects: precarious labor positions at the bottom of the career ladder are more likely to respond "Don't know" while positions at the top of the career ladder are more likely to respond "Not applicable" (See Appendix C). To take advantage of all the information available, we use the EM algorithm to estimate the most likely covariance matrix (Little and Rubin 1989), with auxiliary variables on job and workplace conditions to make the MCAR assumption more plausible and reduce bias (Collins, Schafer, and Kam 2001) (see Appendix C).

The second dimension of employment relations (reward types) was assessed with four dichotomous items asking respondents if earnings from their main job include: "Payments based on the performance of the company where you work?", "Payments based on the performance of your

\footnotetext{
${ }^{8}$ Alternative propositions include the differentiation of four higher classes in higher and lower technocrats and socio-cultural specialists proposed by Güveli and De Graaf (2007), or the three-fold horizontal differentiation across work logics proposed by Oesch (2006). These propositions are based on different conceptual frameworks than employment relations theory. Hence, they cannot be reconciled with EGP-like measures.

${ }^{9}$ This simple subdivision of the upper class has the advantage of being reproducible in all datasets containing the information on supervision and ISCO code that is necessary to build EGP or ESEC.
} 
team/department?", "Income from shares in the company you work for?", "Advantages of other nature (e.g., medical services, access to shops, etc.)?" ${ }^{10}$ The items were coded in such a way that higher scores indicate more diffuse remuneration criteria. In the analytical sample $96 \%$ of cases have valid answers. Missingness is not associated with social class. Missing items are due to "Don't Know" and "Refusal" answers (2\%) and due to an erroneous filter in the 2010 wave ( $2 \%$, see appendix C).

For the construct validation analyses, we choose earnings, contract type, two autonomy scales and the International Socio-Economic Index (ISEI) as alternative measures of occupational advantage. Hence, we primarily focus on labor market indicators. In the EWCS, respondents were surveyed on their net monthly earnings in euros from their main paid job. If they were unable to answer or refused, they were asked to indicate their income band (in 12 categories); in this case we take the midpoint of this band. To account for the skewed distribution of this variable, we take the natural log of income and zstandardize it. Contract type differentiates permanent contract holders from respondents with a temporary or fixed-term contract. The decision autonomy scale available in the EWCS data is based on five items reflecting the extent to which workers can influence decisions that are important for their work (e.g., "you are consulted before objectives are set for your work"), while the work autonomy scale refers to workers' control over the order of tasks, their speed and the method to implement them. The wording of these items is available in Appendix H. ISEl is a score ranging between 16 and 90 that reflects the level of income and education of respondents in different occupations (Ganzeboom, De Graaf and Treiman 1992). It is coded based on ISCO-08 codes using the 'iscogen' package in Stata (Jann 2019). This selection of outcomes reflects data availability, but it is also consistent with an understanding of social class as the economic dimension of social position, rather than as an omnibus measure of social position (Bukodi and Goldthorpe 2012). Therefore, "it is in economic life that the

\footnotetext{
${ }^{10}$ It could be argued that these items are better fit for the private sector than for the public sector. However, sensitivity analyses show that a dummy variable for private vs. public sector does not mediate social class gradients in diffuse payment methods (Bihagen 2008).
} 
implications for individuals of the class positions that they hold should be most immediately apparent" (Goldthorpe and McKnight 2006:12). Appendix B provides descriptive statistics for all variables.

\subsection{Modeling}

We used Principal Component Analysis (PCA) to summarize the items of each dimension. PCA reduces a correlation matrix of several items to a linear combination of uncorrelated continuous variables the principal components $(\mathrm{PC})$ - that preserves as much variance of the original items as possible (Jolliffe 2002; Jolliffe and Cadima 2016). Information that is not associated with the linear combination of extracted components is not used to derive the PC scores. We marshalled PCA instead of factor analysis because we started from a well-defined theoretical framework (employment relations) and aimed to build indices that could measure its core components, namely time horizon and reward types. ${ }^{11}$ By favoring PCA over factor analysis, we did not assume to identify a common cause for the distribution of employment relations and thus restrained from conflating the measurement of employment relations with the analysis of their underlying mechanisms.

We ran the two PCAs for indicators of time horizon and payment types on pooled country data to establish a common metric for the pooled regression models described below. The correlations with the corresponding scores estimated separately for each country were systematically above 0.95 . As regards the time horizon items, the first PC captured $44 \%$ of the variance in the items with an eigenvalue of 1.33. The other two PCs had eigenvalues below 1 and were hence discarded. PC item loadings ranged from 0.55 to 0.59 . As regards the four dichotomous items on reward types, we conducted a PCA on the tetrachoric correlation matrix of the raw data. The first PC captured $61 \%$ of

\footnotetext{
${ }^{11}$ Previous studies used also latent class analysis to inductively identify different types of employment relations from the joint distribution of indicator variables (Birkelund et al. 1996; Evans and Mills 1998; Zou 2015). In this approach, an increasing number of classes are fitted to the data and the best-fitting model can be chosen on the basis of various criteria. This decision relies somewhat on the researcher's judgement and results may not be easily replicable (Nylund, Asparouhov and Muthén 2007)
} 
the variance in the items with an eigenvalue of 2.44. The other PCs were discarded with eigenvalues below 1 . Item loadings on the first component ranged from 0.44 to $0.55 .^{12}$

\section{Validation strategy}

In the criterion validation analyses, we regressed the two continuous PC scores of time horizon and payment types on social class. In a first step, we ran pooled OLS models to assess the overall pattern of association with social class, controlling for gender, age, age squared, and country of birth. By contrasting the four operationalizations of social class described above, we assessed the assumed homogeneity of the salariat class and tested the proposed subdivisions directly. In a second step, we investigated to what extent the relation between social class and employment relations differs between genders by running separate pooled models for men and women. In a third step, we examined class differences in employment relations across countries. For steps one and two, we pooled EWCS country data from waves 2010 and 2015 and estimated the beta coefficients recovered from the following regression equation:

$y_{d}^{S}=\sum_{k=2}^{K} \beta_{k}^{S} X_{k}+\beta_{8} X_{\text {Mig }}+\beta_{9} X_{\text {Women }}+\beta_{10} X_{\text {Age }}+\beta_{11} X_{\text {Age }}^{2}+\beta_{12} X_{2015}+\sum_{n=2}^{N} \beta_{n} X_{n}$

where $y_{d}^{S}$ denotes an employee's score on either of the two dimensions of employment relations and the superscript $\mathrm{S}$ denotes the studied class scheme, $\beta_{k}^{S}$ are the beta coefficients associated with being in the $\mathrm{k}_{\mathrm{th}}$-class relative to the highest class category of scheme $\mathrm{S}$ (either EGP I or ESEC 1 ), $\beta_{8}$ and $\beta_{9}$ are the two effects associated with the dichotomous control variables gender and country of birth, and $\beta_{10}$ and $\beta_{11}$ refer to age and age squared. Finally, $\beta_{12}$ equals the period effect associated with the 2015 wave relative to 2010, and $\beta_{n}$ are the country-specific effects (with Germany as reference category).

\footnotetext{
${ }^{12}$ Negative answers to all items referring to diffuse payment types were common across all classes. This was expected as workers can be rewarded simply with fixed salaries (Goldthorpe and McKnight 2006). This results in a highly left-skewed distribution of the payment method score and a median pay method score of zero in many occupations. However, the mean score does vary substantially across classes, thus revealing differences in the prevalence of diffuse payment types. In Appendix D, we present histograms of payment type scores across classes.
} 
The latter two controls thus purge country fixed effects (e.g., industry differences due to geography) and period or survey effects from the class coefficients.

In step two, we ran the same model separately for men and women. In step three, we fitted equation (2) separately to each country sample with superscript $N$ denoting country. In this step, we standardized the beta coefficients to make them comparable across countries.

$y_{d}^{N}=\sum_{k=2}^{K} \beta_{k}^{N} X_{k}+\beta_{8}^{N} X_{M i g}+\beta_{9}^{N} X_{W o m e n}+\beta_{10}^{N} X_{A g e}+\beta_{11}^{N} X_{A g e}^{2}+\beta_{12}^{N} X_{2015}$

In step three, we quantified the overall strength of class effects using the kappa index (Manza et al. 1995), which is the country-specific standard deviation of the parameters referring to each class:

$$
\kappa^{N}=\sqrt{\frac{1}{K} \sum_{k=2}^{K}\left(\beta_{k}^{N}-\bar{\beta}_{k}^{N}\right)^{2}}
$$

where $\kappa^{N}$ denotes the kappa value for nation $\mathrm{N}$ equaling the standard deviation of the seven nationspecific class effects relative to the higher salariat class. The larger its value for a given country, the more pronounced the class differentials in employment relations in this country.

For the construct validation analyses, we assessed the patterns of association between ESEC or EGP and the labor market indicators (earnings, contract type, the two work autonomy scales and ISEI) described above using either OLS regression or linear probability models. All models control for gender, country of birth, age and age squared. ${ }^{13}$ We regress these outcomes on social class based on the pooled data set of all 31 countries.

All regression models are estimated using sampling and post-stratification weights. In the figures below we report the point estimates and the corresponding confidence intervals. The statistical significance of differences between coefficient pairs is assessed with Wald tests. All differences

\footnotetext{
${ }^{13}$ Coefficient estimates and model statistics are provided in Appendix $\mathrm{F}$
} 
between social classes that we comment on in the text are statistically significant at the $5 \%$-level (the full test results are reported in Appendix G). The syntax to replicate our results is available upon request to the authors.

\section{Results}

\subsection{Criterion validation analyses}

\subsubsection{Comparing ESEC and EGP}

Figure 4 plots the unstandardized beta coefficients displaying the net association between ESEC or EGP and the time horizon (left graph) and reward type (right graph) scores. The coefficients were estimated on the pooled data (equation 1), taking the higher salariat class as reference category. ${ }^{14}$ Figure 4 shows that the pattern of class differences is highly similar for EGP and ESEC: point estimates are virtually identical and in 10 out of 12 cases confidence intervals for class parameters of the two schemes overlap. The similarity of empirical patterns between the two class schemes extends to all results reported below, which suggests they are highly interchangeable measures of employment relations. For simplicity, we only present results for ESEC and report those for EGP in Appendix E.

Figure 4 also shows that class differences are more pronounced with regard to the time horizon dimension than reward types. The coefficient for the most disadvantaged ESEC class (routine workers) is -0.76 for time horizon and -0.48 for reward type. Hence in comparison, the magnitude of class differentials for the second dimension is small to moderate.

\subsubsection{Employment relations and hierarchical differences between social classes}

For both outcomes we detect vertical differences between salariat, intermediate and working classes in figure 4, as reported in earlier validation studies based on a limited number of countries. However, we also detect class differences within the same vertical level. First, employment relations in the lower salariat feature shorter time horizons and less diffuse reward types than those of the higher salariat, 
thus challenging the notion of a unified service class. In fact, reward types in the lower salariat resemble those of the intermediate classes to such an extent that these negligible differences were not statistically significant despite the large sample size.

Second, the two intermediate classes display highly similar values on both dimensions and are clearly distinct from the upper and working classes, a result that confirms their vertical location within the class hierarchy. Moreover, results partly support the claim that these two classes have qualitatively different forms of mixed employment relations. Specifically, higher-grade blue-collars' employment relations are more favorable with regard to reward types but do not score substantively higher on the time dimension compared to those of their white-collar counterparts.

Third, we found evidence of further vertical differences at the bottom of the class structure. First, the employment relations of lower-grade white-collar workers differ significantly in both dimensions from those of lower-grade blue-collar and routine workers, positioning them in-between the intermediate and the lowest classes. Second, routine workers experience the least favorable employment relations with regard to the time horizon, while they are similar to those of lower-grade blue-collar workers with regard to reward types. Overall, these results suggest that, based on their own criterion of employment relations, EGP and ESEC are more hierarchical than theoretically assumed. 
Figure 4: Class coefficients and their $95 \%$ confidence intervals obtained from regressing time horizon and reward types dimensions separately on EGP and ESEC classes

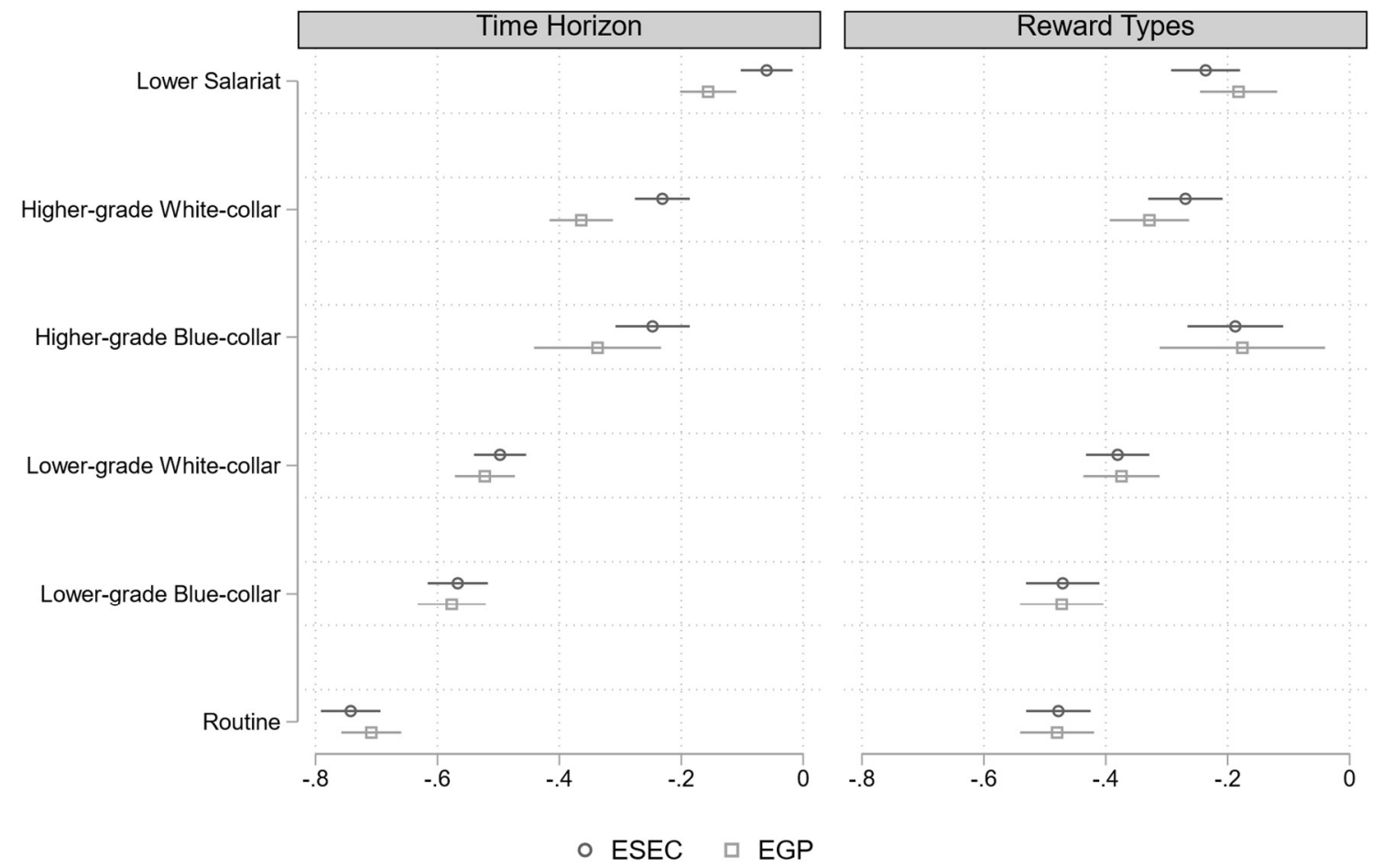

Note: Weighted data for 31 countries from EWCS 2010 \& 2015. The coefficients of the higher salariat are set to 0 (reference category). Sample sizes: $\mathrm{N}\left(\right.$ Time) $=55,447$ (ESEC) / 55,444 (EGP) ${ }^{15}$ and $\mathrm{N}($ Payment $)=59,884$ (ESEC) / 59,880 (EGP). Coefficients obtained from equation (1).

${ }^{15}$ Differences in sample sizes between EGP and ESEC follow on from differential class assignment of members of the armed forces. EGP assigns no classes, whereas ESEC assigns a class based on the vertical position within the military. 
Next, we assess the internal heterogeneity of the two salariat classes with respect to the distinction between managerial and professional occupations. Figure 5 displays regression coefficients (equation 1) estimated with the four alternative categorizations described above, with higher-grade blue-collars as the reference category. Model 1 contrasts a unified salariat class with higher-grade white-collar and blue-collar employees, in line with standard assumptions. Model 2 vertically differentiates the lower and higher salariat, while Model 3 replaces this distinction with the distinction between professionals and managers. Model 4 jointly introduces both differentiations, resulting in four subdivisions within the upper class: higher and lower managers and higher and lower professionals. 
Figure 5: Class coefficients and their $95 \%$ confidence intervals for alternative specifications of higher classes and higher-grade white-collar intermediate positions

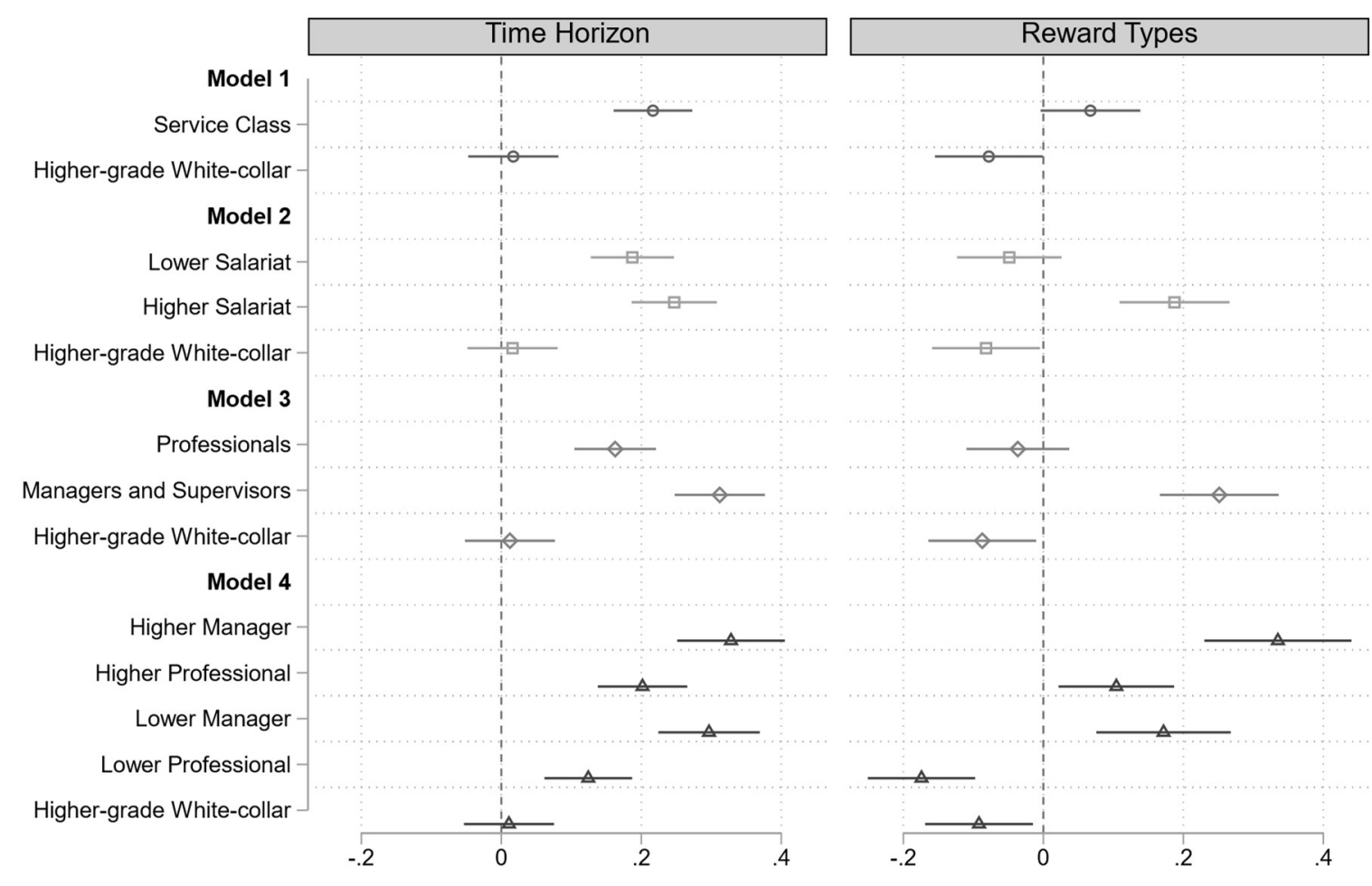

Note: Weighted data for 31 countries from EWCS 2010 \& 2015. Four independently estimated regressions with alternative categorizations of the salariat. Reference category: higher-grade bluecollar workers. Sample sizes $N($ Time $)=55,447$ (ESEC) $/ 55,444$ (EGP) and N(Payment) $=59,884$ (ESEC) / 59,880(EGP). 
Model 1 reveals pronounced differences between the unified salariat and the intermediate classes with regard to time horizons, but smaller differences in reward types. However, Models 2 and 3 highlight further systematic heterogeneity within the upper class with regard to employment relations. According to Model 2, the higher salariat scored higher than the intermediate classes on both outcomes, while there were no significant differences between the lower salariat and higher-grade white-collars in terms of time horizon, or between the lower salariat and higher-grade blue-collars in terms of reward types. The results of Model 3 are even more damaging for the standard assumption of a unified service class, as professionals score below managers on both dimensions and are barely distinguishable from the intermediate classes in terms of reward types scores. Model 4 shows that higher and lower managers and higher professionals are offered more favorable employment relations than lower professionals. This difference is substantial and statistically significant for both dimensions of employment relations, thus challenging the standard assignment of lower professionals to the upper class in ESEC and EGP.

Moreover, lower managers score between higher professionals and higher managers in terms of their employment relations' time horizon, with negligible differences in terms of reward types if compared to higher professionals. Overall, these results challenge the assumed homogeneity of employment relations within the salariat classes and suggest that the real demarcation line between upper and intermediate classes runs between lower professionals and the other fractions of the salariat classes. ${ }^{16}$ Appendix $J$ reports the results of a two-way ANOVA analysis that formally tests the statistical significance of the two divides between higher and lower salariat classes and between managers and professionals. Results show that both are significant and that the divide between managers and

\footnotetext{
${ }^{16}$ Repeating these analyses with the EGP schema yields significant differences between higher and lower managers with regard to the time horizon (ref. Appendix E). Moreover, the associated coefficient of lower managers is smaller than that of higher professionals, indicating that EGP does a better job in accounting for differences between higher and lower positions within the service class than ESEC does in the salariat with regard to the time dimension.
} 
professionals explains substantially more variation of the two dimensions of employment relations than the divide between higher and lower salariat classes.

In order to further investigate which lower salariat professions blur the boundaries of employment relations between upper and intermediate classes, we compared the average scores on the two dimensions for the detailed, 3-digit ISCO-08 occupational categories within the lower salariat (Appendix D). The highest deviations of quantitative importance (i.e. occupations with more than 100 cases) with regard to time horizon and reward types scores involve medical associate professionals (medical and pharmaceutical technicians; nursing and midwifery professionals), educational professions (all teachers below Higher Education), mid-rank bureaucrats in the public sector (government regulatory associate professionals), librarians, archivists and curators, journalists, writers and other artistic professions. It may be noted that women are overrepresented in several of these lower professional occupations, but since the models presented in this section control for gender, this could not have driven the results. However, the relation between class and employment relations might differ between men and women, as discussed in the next section.

\subsubsection{Gender differences in the criterion validity of ESEC}

Figure 6 presents class differences in employment relations estimated separately for men and women, in order to assess whether ESEC displays equal criterion validity across genders (Appendix E Table E3 reports similar results for EGP). The graph shows class coefficients and their $95 \% \mathrm{Cls}$ pertaining to the time horizon (left graph) and reward types (right) scores for women (circles) and men (squares). The reference categories are, respectively, women and men in the higher salariat. 
Figure 6: Class coefficients and their 95\% confidence intervals obtained from regressing time horizon and reward types dimensions on ESEC classes by gender

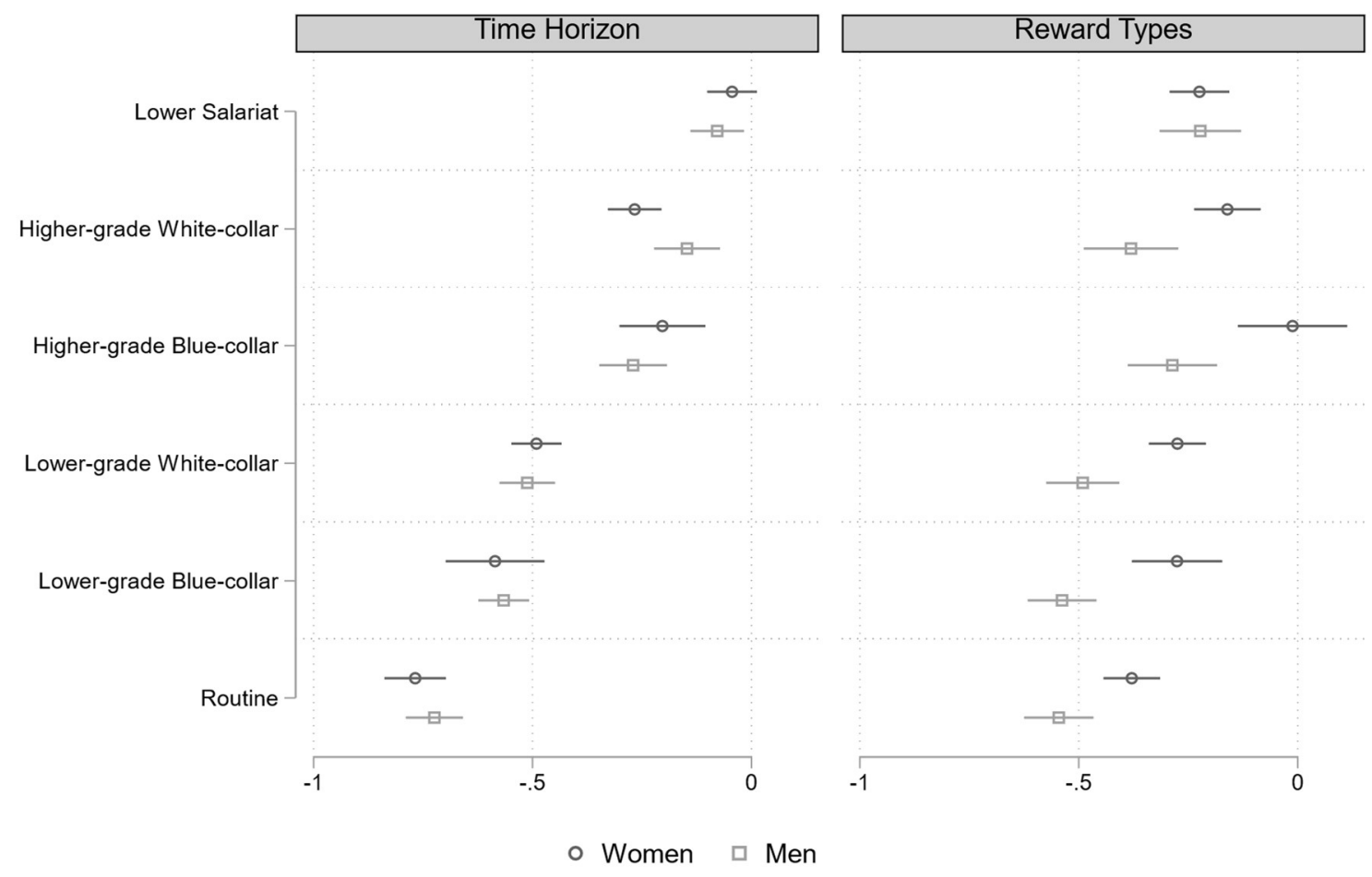

Note: Weighted data for 31 countries from EWCS 2010 \& 2015. Reference category: higher salariat.

Sample sizes N(Time) $=26725$ (Men) and 28723 (Women) and N(Payment)= 28687 (Men) and 31197

(Women). Coefficients obtained from equation (1) for each gender sample. 
Comparing point estimates at a glance yields similar association patterns between class and employment relations among men and women. Indeed, for time horizon a model incorporating an interaction term between class and gender does not improve model fit compared to the additive model displayed in equation 1 (Appendix L). However, with regard to reward types, the interaction is statistically significant. Indeed, as can be seen in figure 6 , women's class positions are poorly differentiated in terms of reward types. In particular, women in the lower salariat do not significantly differ from those in intermediate and working-class positions. Unexpectedly, female higher-grade blue-collars resemble the higher salariat with regard to reward types. ${ }^{17}$ Overall, these results indicate that the reward types characterizing the contractual arrangements of women are less differentiated along social classes than those of men.

\footnotetext{
${ }^{17}$ The extreme score on the reward types dimension for female higher-grade blue-collar workers probably reflects the unusually high levels of selectivity and the small sample sizes of this heavily male-dominated category (six men for every woman).
} 


\subsubsection{Cross-national differences in the criterion validity of ESEC}

Figure 7 presents the kappa indices regarding the time horizon (left) and reward types (right) dimensions of employment relations for each of the 31 countries under examination. For any given country, larger kappas indicate that class differences in employment relations are more pronounced in this country. Markers to the left (right) of the dashed vertical lines indicate lower (higher) kappas relative to the country average. Figure 7 suggests that countries differ little with regard to the overall magnitude of class differences in both dimensions of employment relations. As regards time horizon, the average kappa is 0.11 and country values range between .07 and .14 for virtually all countries, with Greece as an outlier displaying more pronounced class differences ${ }^{18}$. Class stratification according to reward types displayed even less variation, with most countries scoring between .07 and .12 . In appendix I, we present similar results for EGP.

We formally tested country differences in the associations between class and employment relations by comparing the fit statistics of a model applying equation 1 to the pooled data with an alternative model incorporating interaction effects between country and social class. Results show that the former clearly outperform the latter, thus confirming that country similarities outweigh differences (results reported in Appendix L). Moreover, in Appendix $\mathrm{K}$ we show that partitioning variance into two levels shows that only $7 \%$ of the variation in reward types and $15 \%$ in time horizon lies between countries, with the rest being accounted for by individual-level differences.

Country differences are not only small, but also non-systematic. In particular, figure 7 reveals that the country clusters of western continental Europe, Southern Europe and Eastern Europe display marked internal heterogeneity. Scandinavian countries score slightly below-average on both dimensions and the same is also true for the UK and Ireland to some extent. To further investigate the possibility of systematic country differences, we regressed the country kappas on indicators for country clusters and

\footnotetext{
${ }^{18}$ Greece was characterized by a dualized class cleavage opposing the salariat and intermediate classes with similar employment relations to the highly disadvantaged working classes.
} 
on measures of economic modernization (GDP per capita in purchasing power parities, $\%$ tertiary educated, \% employed, \% workers in ISCO major groups 1 or 2 , and in ISCO major groups 8 or 9). We do not find any indication of systematic country differences, with the exception of a statistically significant and moderately negative association between the share of highly skilled occupations (ISCO major groups 1 or 2) and the kappa values for time horizon scores. Overall, these results indicate that ESEC and EGP display highly similar criterion validity across countries, thus setting a solid ground for comparative research based on these class schemes. 
Figure 7: Country-specific Kappa indices summarizing class differences with regard to employment contract time horizons and reward type
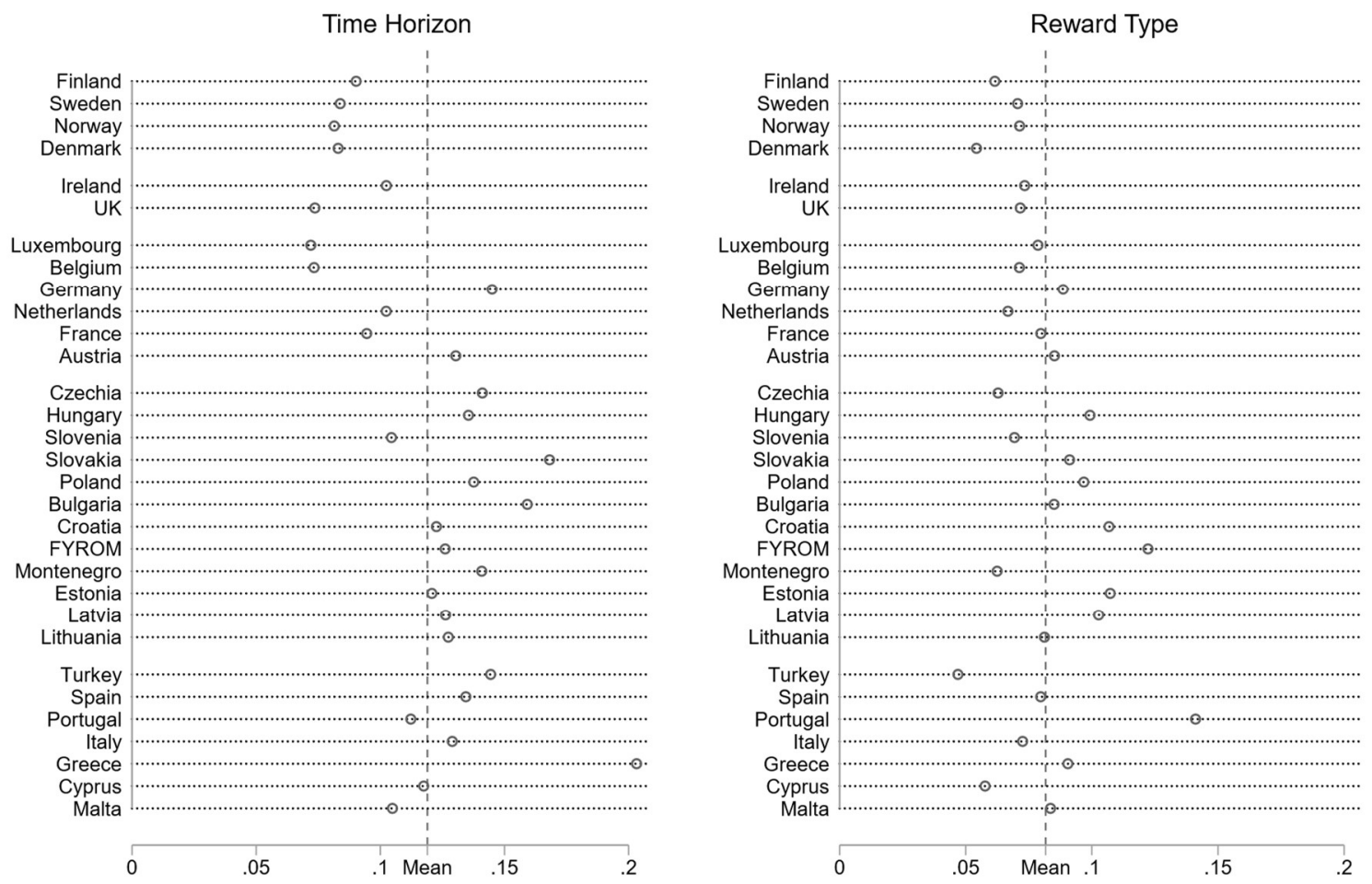

Note: Weighted data for 31 countries from EWCS 2010 \& 2015. Figure displays the national standard deviations of the standardized class regression coefficients from equation (2) from regressions performed separately for each country. 


\subsection{Construct validation analyses}

Turning now to the construct validation analyses, we assessed to what extent ESEC and EGP classes differ with respect to five outcomes: earnings, socio-economic status, permanent vs. fixed-term contracts, work autonomy and decision autonomy. While EGP and ESEC are not supposed to directly measure these characteristics of occupations, the underlying theory predicts that social classes differ with respect to them (Goldthorpe 2007; Rose and Harrison 2010). Hence, these outcomes can be used to assess the construct validity of these class schemes and serve as additional, external benchmarks to assess class hierarchies, considering that they are widely used in stratification research. We regressed each of these outcomes on the social class categories, controlling for the same socio-demographic characteristics as before. Following the results of section 5.1.2, we differentiated the salariat in its four constitutive class subdivisions. Higher-grade white-collars were the reference category.

Figure 8 plots the regression coefficients for the ESEC classes, demonstrating that class differences are especially pronounced regarding socio-economic status and earnings, and also large in terms of work and decision autonomy. Class differences in access to permanent contracts are small among the upper and the intermediate classes, which display a substantial advantage over the working classes. For the other four indicators, two systematic patterns emerge: higher managers enjoy the most advantageous occupational prospects while routine workers display the least advantageous ones. Hence these two classes define the extreme poles of the class hierarchy, further corroborating our previous results concerning the existence of vertical divides within both the upper and the working classes. Moreover, within both the upper and the lower salariat, managers outperform professionals in terms of earnings, work and decision autonomy, another result that echoes class patterns in employment relations. Confirming the other salariat cleavages, we find that lower professionals displayed lower income, work and decision autonomy than all other upper class' subdivisions, thus replicating the above patterns for the time horizon and reward types of employment relations. While earning less than lower managers, 
lower professionals, however, outperformed them on the ISEI scale, which is based on the average levels of income and of education of occupations. Hence, when looking at multiple occupational and economic indicators, lower professionals must be clearly located below the other upper classes, while their cultural resources could justify a more favorable placement.

The two intermediate classes display systematically better prospects than all three working classes across all outcomes, while the comparisons with the upper classes point to systematic disadvantages with regard to income, socio-economic status and autonomy. Since none of the two intermediate classes systematically outperform the other, their joint placement in the middle ranks of the class hierarchy is supported. Finally, the point estimates and confidence intervals concerning lower-grade white-collars and lower-grade blue-collars indicate that these two classes enjoy similar occupational prospects and outperform routine workers.

Overall, four major conclusions emerge from these results. First, class patterns for different indicators do not always go in the same direction, showing that the relative prospects of different social classes vary depending on the occupational outcome. Second, the broad patterns of differences between ESEC (or EGP) classes are in accordance with class theory pointing to adequate construct validity. However, our third conclusion is that both the upper and the working classes are more internally heterogeneous than the three-level hierarchy assumption predicts. Finally, our results point to systematic differences between managerial and professional occupations and further challenge the assignment of lower professionals to the upper class. 
Figure 8: Regression coefficients for income, work autonomy, ISEI, and AME on stable contract with confidence intervals, for ESEC

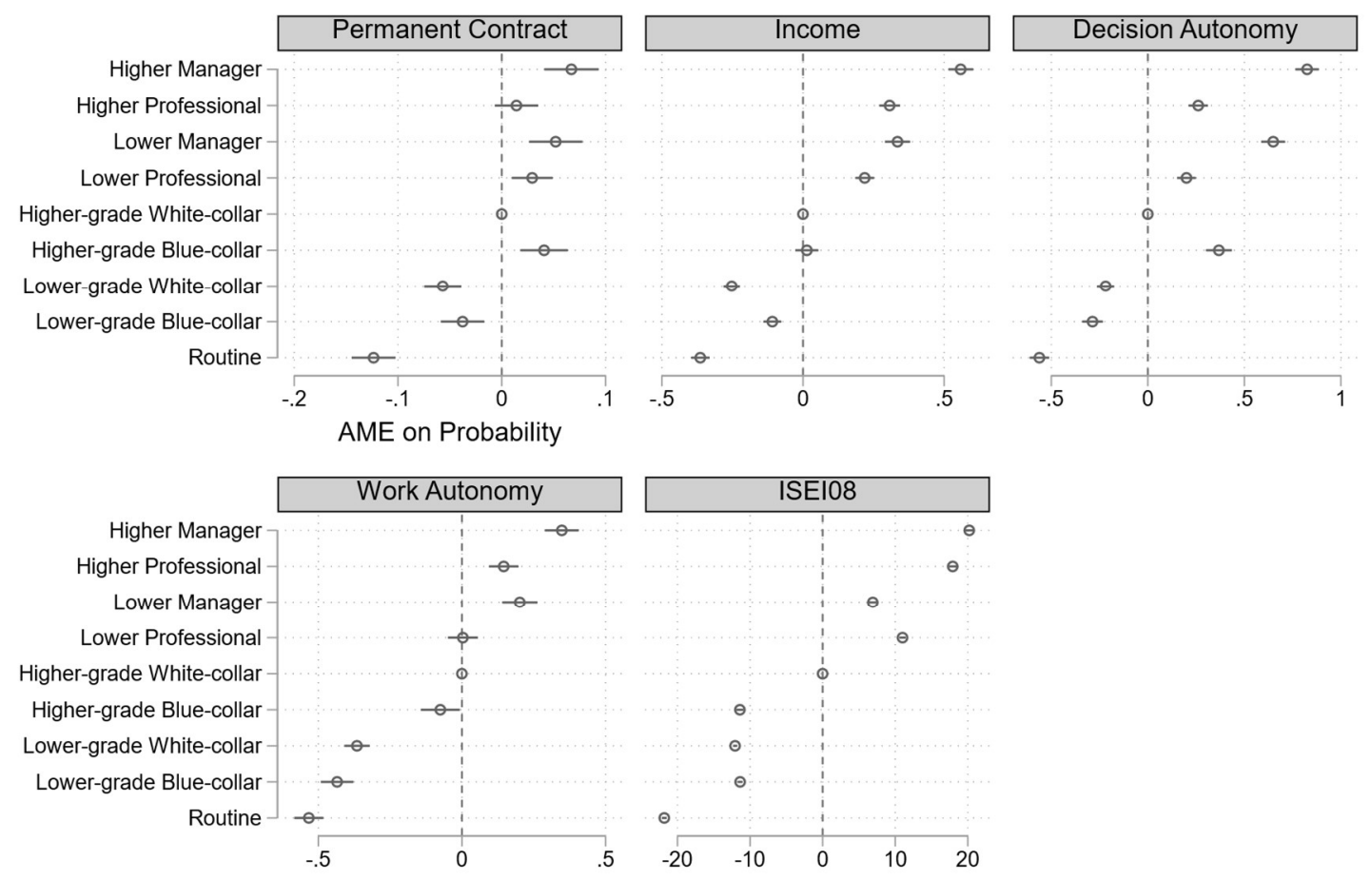

Note: Weighted data for 31 countries from EWCS 2010 \& 2015. Figure displays unstandardized coefficients and AMEs (permanent contract). 


\subsection{Robustness checks}

In this section, we briefly summarize the results of several robustness checks. First, further analyses show that the definition of the analytical sample does not affect our conclusions. In particular, the pattern of results is unchanged when including only respondents working at least 20 hours per week, as was done in some previous validation studies. Moreover, following standard practice in class analysis, we included previously employed individuals who were out of work the time of the interview. Repeating the analyses for employed respondents only yields virtually identical results, indicating that the standard practice of class analysis is justified (Appendix E).

Second, the results are robust to alternative measurements of the dependent variables, in particular to alternative data reduction techniques for the underlying items (Appendix C). The PCA scores for the two dimensions of employment relations display high Pearson correlations $(r>=0.95)$, both with scores based on simple additive indexes and with scores from a confirmatory factor analysis. Additionally, PCA scores estimated from the pooled data and corresponding scores separately estimated for each country prove nearly identical with correlations above 0.95 .

A third set of sensitivity analyses concerns the class variables. We compared the results obtained when using three-digit and four-digit versions of ISCO-88 and ISCO-08, finding only negligible differences in the association patterns of social class and employment relations across occupational coding schemes or assignment routines. We also compared the reported results based on a narrow definition of supervisory status to those obtained using ISCO-08 titles to define supervisory status, and a third set of results obtained by assigning class solely based on occupational codes without using information on supervisory status. The pattern of results is unchanged (Appendix E). Finally, dropping the control variables described in section 4.2 does not alter the patterns of class differences in employment relations to any significant extent, nor does the inclusion of a dummy variable marking employment in the public sector. 


\section{Conclusions}

This study assessed the criterion and construct validity of ESEC and EGP by analyzing class differences in employment relations and labor market outcomes in 31 countries. The theoretical framework of these class schemes implies that employment relations are differentiated on a bi-dimensional space defined by their time horizon and reward types. Class differences along these two dimensions reflect two explanatory mechanisms: human asset specificity and monitoring problems. Whereas most previous criterion validation studies assessed only one of the two dimensions of employment relations or conflated them with measures of their explanatory mechanisms, in this work we could differentiate between the two dimensions relying on the data of the EWCS. Moreover, this study contributes to the literature with a large-scale, comparative validation analysis assessing the criterion validity of both schemes separately for men and women and across multiple operationalizations that are common in class analysis. Furthermore, the construct validation analyses asses class differences with respect to multiple occupational indicators relevant to stratification research.

Our results offer some good news for users of EGP-like schemes. First, differences in employment relations between upper, intermediate and working classes largely follow the patterns predicted by the theory, indicating that these class schemes display good criterion validity. This conclusion may be tempered, however, when considering that class differences are not very large. For instance, the distance between the higher salariat and the two intermediate classes in ESEC is below 0.3 standard deviations for both dimensions of employment relations. Moreover, by differentiating between these two dimensions, we could show that the two intermediate classes (higher-grade white-collar and higher-grade blue-collar positions) do not display the qualitative differences that were invoked to treat them as separate classes.

Second, we found that country variations in the magnitude of class differences in employment relations are small and unsystematic. This is an important conclusion because EGP-like schemes are used extensively in comparative research, with little evidence of their criterion validity across countries 
with different economic features and institutional arrangements. Since these schemes display similar criterion validity across countries, country differences in social class patterns can be interpreted in substantive terms, and not merely as measurement artifacts.

Third, we found that gender commonalities exceed differences with regard to class-based patterns of employment relations. The overall similarity of the association patterns between men and women provides solid ground for gender-based analyses of class inequalities using EGP-like schemes. However, class differences in terms of reward types are far less pronounced among women. Occupational sex segregation and the devaluation of female-typed labor may contribute to explaining gender differences in terms of reward types (Levanon, England and Allison 2009; Hausmann, Kleinert and Leuze 2015; Blau and Kahn 2017). Our results thus call for further exploration of the gender-specific mechanisms explaining why women from all classes display less variation than men with regard to reward types (Goldthorpe and McKnight 2006; Bihagen 2008).

A fourth reassuring finding is that ESEC and EGP measure employment relations equally well, and this conclusion applies to different operationalizations of these class schemes (3-digit and 4-digits ISCO, 1988 and 2008 ISCO, with or without supervision information, with or without individuals who are not currently employed). Owing to data availability constraints, EGP-like schemes are often built in several different ways: our results indicate that these different operationalizations are largely interchangeable.

At the same time, a major limitation of EGP-like schemes is that they do not discriminate well between upper-class positions, even when using the theory's preferred yardstick of employment relations. These class schemes place the two salariat classes together at the top of a three-level hierarchy, a tier which accounts for about two fifths of the workforce in many developed countries. This simple fact invites us to rethink the boundaries of privileged classes. This limitation has served as an argument to abandon EGP-like schemes in favor of alternative schemes incorporating and theorizing more finegrained distinctions at the top (Esping-Andersen 1993; Oesch 2006; Güveli and Graaf 2007; Hertel 
2017). Construct validation analyses contrasting EGP-like schemes with their competitors are an important avenue for future research (Weeden et al. 2007; Lambert and Bihagen 2014).

Whatever the merits of these alternative approaches, abandoning EGP-like schemes would come at the cost of introducing a major discontinuity with four decades of class analysis dominated by EGP. Moreover, the encouraging results of previous validation studies and the four desirable properties of these class schemes identified in this study constitute compelling arguments against such a drastic solution. The overriding dominance of EGP-like schemes in class analysis in recent years (Barone et al. 2020) testifies to their persistent popularity among empirical researchers. Based on our results, we therefore identify three pragmatic ways to proceed.

A first reaction to the above problem would be to continue using EGP-like schemes while ignoring the postulated three-level hierarchy, thus treating the distinction between higher and lower salariat classes as a genuinely vertical difference. For example, this is the solution found in studies modeling access to the upper class as access to the higher salariat only (Bernardi and Ballarino 2016). Our results provide some justification for this pragmatic solution, to the extent that we found that employment relations in the lower salariat display a shorter time horizon and less diffuse rewards than in the higher salariat, and that the former displays lower earnings and socio-economic status, as well as lower job autonomy and less frequent access to permanent contracts. Our study thus shows that the distinction between the two salariat classes is unambiguously hierarchical.

However, our results also point to the limitations of this pragmatic solution, which downplays the heterogeneity between managerial and professional occupations of the salariat classes. The aggregation of managers and professionals into an undifferentiated upper class is possibly the most distinctive feature of EGP-like schemes compared to other class schemes. Critics of these schemes provided evidence that managers and professionals differ in several respects, including income, mobility patterns, political preferences and voting patterns (Oesch 2006; Kitschelt and Rehm 2014; Hertel 2017). However, they did have not assess the heterogeneity of these two class subdivisions with 
regard to employment relations, that is, the theoretical construct which underpins EGP-like schemes. Conversely, previous criterion validation studies using indicators of employment relations did not address differences between managers and professionals. Our study provides this missing piece of evidence and reaches two major conclusions. On the one hand, the employment contracts of lower professionals display shorter time horizons and less diffuse reward types than those of lower managers and of higher managers and professionals. On the other hand, lower managers significantly differ from higher professionals in terms of their employment relation's time horizon but not reward type. The construct validity analyses replicate these two key patterns with respect to class differences in income, work and decision autonomy.

Hence, a second solution to the above problem of differentiating upper-class positions is to separate lower professionals from the rest of the upper class. This solution is easy to implement and can be justified within the theoretical framework of EGP-like schemes to the extent that professions in the lower salariat (e.g., librarians, high school teachers, nurses) involve lower asset specificity and fewer monitoring problems than managerial occupations and professions in the higher salariat (e.g., lawyers, university professors, doctors). Indeed, Goldthorpe (2006) suggested that workers in the lower salariat may be offered an attenuated form of the service contract, although our results indicate that this applies only to lower professionals.

A third solution is to develop EGP-like schemes by integrating the distinction between managers and professionals within both the lower and higher salariat, as recently suggested by Ganzeboom (2018) with the ISEC scheme. Indeed, we found that higher managers outperform higher professionals and that lower managers outperform lower professionals with respect to the time horizon and type of rewards characterizing their employment relations. These pairwise comparisons were not always large nor statistically significant, but when we contrasted managerial and professional occupations altogether, we detected a statistically significant, sizeable advantage of the former. 
This third solution invites further differentiation without necessarily casting aside the framework of employment relations. ${ }^{19}$ Moreover, differences between managers and professionals in terms of cultural orientations, lifestyles and voting patterns are well-documented (Weeden and Grusky 2005; Oesch 2006; Kitschelt and Rehm 2014). Hence, this solution has the advantage of promoting stronger connections between the analysis of class inequalities and the analysis of class identities and class mobilization. Another important consideration is that the aggregation of managers and professionals conceals gender inequalities at the top of the class hierarchy. To illustrate, in the EWCS data the share of male workers is $62 \%$ in both higher and lower managerial occupations, while the higher professions display a gender balance (51\%) and men are a minority in the lower professions (37\%).

Our results also challenge the three-level hierarchy assumption of EGP-like schemes with regard to differences within the working class. In particular, we found that contracts in routine occupations (corresponding to EGP VII) display significantly shorter time horizons than those of lower-grade bluecollars (EGP VI) and white-collars (IIIb). We did not find the same pattern for reward types, but we suspect that this reflects the main limitation of the underlying indicators available in the EWCS, namely, that they do not include piecewise nor timewise payment methods, and thus do not discriminate well between employment relations at the bottom of the class hierarchy. Moreover, the construct validation analyses indicate that routine workers are offered permanent contracts less often and enjoy lower income and work autonomy than the other working classes.

Moreover, the hierarchical position of lower-grade white-collars (IIIb) in empirical research is ambiguous, as they are variously merged with higher-grade white-collars (IIla), with lower-grade bluecollars (VI) or with routine occupations (VII). Erikson and Goldthorpe (1992) suggested that the third solution is preferable, but only in the case of women. Our results indicate that the second solution is far more satisfactory than the others for both genders, thus placing lower-grade blue and white-collars

\footnotetext{
${ }^{19}$ Goldthorpe (2006) acknowledged that new public management reforms introducing accountability procedures in several professions may undermine the logic of the service contract in these occupations. However, he discarded this possibility and never theorized differences between managers and professionals in terms of employment relations.
} 
together and above routine occupations. Overall, we conclude that a five-level hierarchy incorporating vertical distinctions within both the upper class and the working class is a more realistic representation of class hierarchies in contemporary societies. ${ }^{20}$

The results on class differences in ISEI, however, may seem to contradict our conclusions and recommendations. Lower managers' socio-economic status is not higher than that of lower professionals, nor do the working classes score higher than routine workers. ISEl reflects the levels of income and education of different occupations: lower professionals and routine workers display lower earnings, but not lower levels of education or cultural resources than their counterparts (Meraviglia, Ganzeboom and De Luca 2016). Hence, using EGP and ESEC under the three-level hierarchy assumption might be justified if these class schemes are conceived of as synthetic measures of social position averaging economic and cultural resources. In mobility research, for instance, social class is employed as such an omnibus measure of social position (Erikson and Goldthorpe 1992).

The recommendation then is clear: if analysts understand social class as a summary index of social position, they might just stick to the standard EGP-like measures. Such broad understanding of class, however, comes at a high price. The upper class of EGP-like schemes will be too large and heterogeneous to effectively identify privilege. Moreover, this omnibus approach conflates class effects with the effects of cultural and social resources, which must be captured by separate variables (Bukodi and Goldhorpe 2013; Bukodi et al. 2018; Rose and Harrison 2010). Instead, social scientists can employ these class schemes specifically as measures of the economic dimension of social position and interpret class effects as emerging from employment relations (Goldthorpe, McKnight 2006). Then, they should introduce the proposed distinctions.

\footnotetext{
${ }^{20}$ Some might object that class schemes could be simply replaced by gradational measures introducing even more fine-grained vertical distinctions. However, the proposed modifications preserve important horizontal distinctions among the working classes (lower-grade blue-collars and white-collars), the intermediate classes (higher-grade blue-collars and white-collars, independent workers) and the upper classes (managerial and. professional occupations).
} 


\section{References}

Barone, Carlo, Florian R. Hertel, and Oscar Smallenbroek. 2020. "What We Think When We Speak About Stratification." SocArXiv. January 7. https://doi.org/10.31235/osf.io/rpfza

Beller, Emily. 2009. "Bringing Intergenerational Social Mobility Research into the Twenty-first Century: Why Mothers Matter." American Sociological Review 74(4):507-28. https://doi.org/10.1177/000312240907400401

Bernardi, Fabrizio and Gabriele Ballarino, eds. 2016. Education, Occupation, and Social Origin: A Comparative Analysis of the Transmission of Socio-Economic Inequalities. Cheltenham, UK: Edward Elgar Publishing.

Bihagen, Erik. 2008. "Does Class Matter Equally for Men and Women?: A Study of the Impact of Class on Wage Growth in Sweden 1999-2003." Sociology 42(3):522-40. https://doi.org/10.1177/0038038508088838

Bihagen, Erik, Magnus Nermo, and Robert Erikson. 2010. "Social Class and Employment Relations: Comparisons between the ESeC and EGP Class Schemas Using European Data." Pp. 89-113 in Social Class in Europe: An Introduction to the European Socio-Economic Classification, edited by D. Rose and E. Harrison. London: Routledge.

Birkelund, Gunn E., Leo A. Goodman, and David Rose. 1996. "The Latent Structure of Job Characteristics of Men and Women." American Journal of Sociology 102(1):80-113. https://doi.org/10.1086/230909

Blau, Francine D. and Lawrence M. Kahn. 2017. "The Gender Wage Gap: Extent, Trends, and Explanations." Journal of Economic Literature 55(3):789-865. https://doi.org/10.1257/jel.20160995

Borsboom, Denny, Gideon J. Mellenbergh, and Jaap van Heerden. 2004. "The Concept of Validity." Psychol Rev 111(4):1061-71. https://doi.org/10.1037/0033-295X.111.4.1061

Brousse, Cécile, Olivier Monso, and Loup Wolff. 2010. "Stable and Consistent with the Employment Relations Theoretical Background? Does the Prototype ESeC Show These Qualities with French Data?" Pp. 186-206 in Social Class in Europe, edited by D. Rose and E. Harrison. London: Routledge.

Bukodi, Erzsébet, Ferdinand Eibl, Sandra Buchholz, Sonia Marzadro, Alessandra Minello, Susanne Wahler, Hans-Peter Blossfeld, Robert Erikson, and Antonio Schizzerotto. 2018. "Linking the Macro to the Micro: A Multidimensional Approach to Educational Inequalities in Four European Countries." European Societies 20(1):26-64. https://doi.org/10.1080/14616696.2017.1329934

Bukodi, Erzsébet and John H. Goldthorpe. 2013. "Decomposing 'Social Origins': The Effects of Parents' Class, Status, and Education on the Educational Attainment of Their Children." European Sociological Review 29(5):1024-39. https://doi.org/10.1093/esr/jcs079

Collins, Linda M., Joseph L. Schafer, and Chi-Ming Kam. 2001. "A Comparison of Inclusive and Restrictive Strategies in Modern Missing Data Procedures." Psychological Methods 6(4):330. https://doi.org/10.1037/1082-989X.6.4.330

Cronbach, Lee J. and Paul E. Meehl. 1955. "Construct Validity in Psychological Tests." Psychological Bulletin 52(4):281-302. https://doi.org/10.1037/h0040957

Erikson, Robert, John H. Goldthorpe, and Lucienne Portocarero. 1979. "Intergenerational Class Mobility in Three Western European Societies: England, France and Sweden." The British Journal of Sociology 30(4):415-41. https://doi.org/10.2307/589632

Erikson, Robert and John H. Goldthorpe. 1985. "Are American Rates of Social Mobility Exceptionally High? New Evidence on an Old Issue." European Sociological Review 1(1):1-22.

Erikson, Robert and John H. Goldthorpe. 1992. The Constant Flux: A Study of Class Mobility in Industrial Societies. Oxford: Clarendon Press. 
Esping-Andersen, Gøsta. 1993. Changing Classes: Stratification and Mobility in Post-Industrial Societies. Newbury Park, CA: Sage Publications.

Eurofound. 2017. European Working Conditions Survey Integrated Data File, 1991-2015. [data collection]. SN: 7363. UK Data Service.

https://doi.org/10.5255/UKDA-SN-7363-4

Evans, Geoffrey. 1992. "Testing the Validity of the Goldthorpe Class Schema." European Sociological Review 8(3):211-32.

https://doi.org/10.1093/oxfordjournals.esr.a036638

Evans, Geoffrey. 1996. "Putting Men and Women into Classes: An Assessment of the Cross-Sex Validity of the Goldthorpe Class Schema." Sociology 30(2):209-34. https://doi.org/10.1177/0038038596030002002

Evans, Geoffrey and Colin Mills. 1998. "A Latent Class Analysis of the Criterion-Related and Construct Validity of the Goldthorpe Class Schema." European Sociological Review 14(1):87-106. https://doi.org/10.1093/oxfordjournals.esr.a018229

Evans, Geoffrey and Colin Mills. 1999. "Are There Classes in Post-Communist Societies? A New Approach to Identifying Class Structure." Sociology 33(1):23-46. https://doi.org/10.1177/S0038038599000024

Gallie, Duncan, Michael White, Yuan Cheng, and Mark Tomlinson. 1998. Restructuring the Employment Relationship. OUP Catalogue.

Gallup Europe. 2010. “Technical Report: 5th European Working Conditions Survey, 2010." UK Data Archive Study Number 6971

Ganzeboom, Harry B. G. 2018 "QUESTIONS AND ANSWERS ON ISEC-08, EGP AND ESEC." Retrieved December 9, 2020 (http://www.harryganzeboom.nl/isco08/qa-isec-08.htm).

Ganzeboom, Harry B. G., Paul M. De Graaf, and Donald J. Treiman. 1992. "A standard international socio-economic index of occupational status." Social science research 21(1):1-56. https://doi.org/10.1016/0049-089X(92)90017-B

Ganzeboom, Harry B. G. and Donald J. Treiman 1996. "Internationally Comparable Measures of Occupational Status for the 1988 International Standard Classification of Occupations." Social science research 25(3):201-39.

https://doi.org/10.1006/ssre.1996.0010

Goldthorpe, John H. 2007. "Social Class and the Differentiation of Employment Contracts." Pp. 10124 in On Sociology: Volume Two: Illustration and Retrospect, edited by J. H. Goldthorpe. Stanford, CA: Stanford University Press.

Goldthorpe, John H. and Abigail McKnight. 2006. "The Economic Basis of Social Class." Pp. 109-136 in Mobility and inequality: Frontiers of research in sociology and economics, edited by S. L. Morgan, D. B. Grusky and G. S. Fields. Stanford, CA: Stanford University Press.

Güveli, Ayse and Nan Dirk De Graaf. 2007. "Career Class (Im)Mobility of the Social-Cultural Specialists and the Technocrats in the Netherlands." European Sociological Review 23(2):185-201. https://doi.org/10.2307/4137362

Güveli, Ayse, Ariana Need, and Nan Dirk de Graaf. 2007. "The Rise of 'New' Social Classes within the Service Class in the Netherlands: Political Orientation of Social and Cultural Specialists and Technocrats between 1970 and 2003." Acta Sociologica 50(2):129-46. https://doi.org/10.2307/20459988

Hausmann, Ann-Christin, Corinna Kleinert, and Kathrin Leuze. 2015. “"Entwertung Von Frauenberufen Oder Entwertung Von Frauen Im Beruf?"." KZfSS Kölner Zeitschrift für Soziologie und Sozialpsychologie 67(2):217-42. https://doi.org/10.1007/s11577-015-0304-y Hertel, Florian R. 2017. Social Mobility in the 20th Century. Wiesbaden: Springer VS.

IPSOS. 2015. "Technical Report: 6th European Working Conditions Survey, 2015." UK Data Archive Study Number 8098

Jann, Ben 2019. "Iscogen: Stata Module to Translate ISCO Codes." http://ideas.repec.org/c/boc/bocode/s458665.html.

Jolliffe, Ian. T. 2002. Principal Component Analysis. New York: Springer. 
Jolliffe, Ian T. and Jorge Cadima. 2016. "Principal Component Analysis: A Review and Recent Developments." Philosophical Transactions of the Royal Society A: Mathematical, Physical and Engineering Sciences 374(2065):1-16. https://doi.org/10.1098/rsta.2015.0202

Katrňák, Tomáš. 2012. "Is Current Czech Society a Social Class-Based Society? The Validity of EGP and ESeC Class Schemes." Sociológia 44(6):678-703.

Kulin, Joakim and Stefan Svallfors. 2013. "Class, Values, and Attitudes Towards Redistribution: A European Comparison." European Sociological Review 29(2):155-67. https://doi.org/10.1093/esr/jcr046

Lambert, Paul S., and Erik Bihagen. 2014. "Using Occupation-Based Social Classifications." Work, Employment \& Society 28(3):481-94. https://doi.org/10.1177/0950017013519845

Levanon, Asaf, Paula England, and Paul Allison. 2009. "Occupational Feminization and Pay: Assessing Causal Dynamics Using 1950-2000 U.S. Census Data." Social Forces 88(2):865-91. https://doi.org/10.1353/sof.0.0264

Little, Roderick J. A., And Donald B. Rubin. 1989. "The Analysis of Social Science Data with Missing Values." Sociological Methods \& Research 18(2-3):292-326. https://doi.org/10.1177/0049124189018002004.

Manza, Jeff, Michael Hout, and Clem Brooks. 1995. "Class Voting in Capitalist Democracies since World War li: Dealignment, Realignment, or Trendless Fluctuation?" Annual Review of Sociology 21:137-62. https://doi.org/10.1146/annurev.so.21.080195.001033

Markus, Keith A. and Chia-ying Lin. 2012. "Construct Validity." Pp. 230-233 in Encyclopedia of Research Design, edited by N. J. Salkind. Thousand Oaks: Sage Publications. https://doi.org/10.4135/9781412961288

McGovern, Patrick, Stephen Hill, Colin Mills, and Michael White. 2007. "Market, Class, and Employment." Oxford ; New York: Oxford University Press.

McKnight, Abigail and Peter Elias. 2003. "Empirical Variation in Employment Relations and Conditions." in A Researcher's Guide to the National Statistics Socio-Economic Classification, edited by D. Rose and D. J. Pevalin. London: SAGE Publications, Ltd. https://dx.doi.org/10.4135/9780857024725.d11

Meraviglia, Cinzia, Harry B. G. Ganzeboom, and Deborah De Luca. 2016. "A New International Measure of Social Stratification." Contemporary Social Science 11(2-3):125-53. https://doi.org/10.1080/21582041.2016.1215512

Mitnik, Pablo A. and Erin Cumberworth. 2018. "Measuring Social Class with Changing Occupational Classifications: Reliability, Competing Measurement Strategies, and the 1970-1980 U.S. Classification Divide." Sociological Methods \& Research 50(1):265-309. https://doi.org/10.1177/0049124118769084

Nylund, Karen L., Tihomir Asparouhov, and Bengt O. Muthén. 2007. "Deciding on the Number of Classes in Latent Class Analysis and Growth Mixture Modeling: A Monte Carlo Simulation Study." Structural Equation Modeling: A Multidisciplinary Journal 14(4):535-69. https://doi.org/10.1080/10705510701575396

Oesch, Daniel. 2006. Redrawing the Class Map. Stratification and Institutions in Britain, Germany, Sweden and Switzerland. Basingstoke: Palgrave Macmillan.

Piketty, Thomas, Emmanuel Saez, and Gabriel Zucman. 2018. "Distributional National Accounts: Methods and Estimates for the United States." The Quarterly Journal of Economics:1-57. https://doi.org/10.1093/qje/qjx043

Pollak, Reinhard, Gerrit Bauer, Müller Walter, Felix Weiss, and Heike Wirth. 2010. "The Comparative Measurement of Supervisory Status." Pp. 138-58 in Social Class in Europe: An Introduction to the European Socio-Economic Classification, edited by D. Rose and E. Harrison. Routledge.

de Regt, Sabrina, Tim Smits, and Dimitri Mortelmans. 2012. "The Relevance of Class in Shaping Authoritarian Attitudes: A Cross-National Perspective." Research in Social Stratification and Mobility 30(3):280-95. https://doi.org/10.1016/j.rssm.2012.03.001

Rose, David and Eric Harrison. 2010. Social Classs in Europe. London: Routledge. https://doi.org/10.4324/9780203930588 
Rose, David, David J. Pevalin, and Karen O'Reilly. 2005. The National Statistics Socio-Economic Classification: Origins, Development and Use. New York, Basingstoke: Palgrave Macmillan.

Tåhlin, Michael. 2007. “Class Clues." European Sociological Review 23(5):557-72. https://doi.org/10.1093/esr/jcm019

Weeden, Kim A., and David B. Grusky. 2005. "The Case for a New Class Map." American Journal of Sociology 111(1):141-212. https://doi.org/10.1086/428815

Weeden, Kim A., Young-Mi Kim, Matthew Di Carlo, and David B. Grusky. 2007. "Social Class and Earnings Inequality." American Behavioral Scientist 50(5):702-36. https://doi.org/10.1177/0002764206295015

Williams, Mark. 2016. "An Old Model of Social Class? Job Characteristics and the NS-SEC Schema." Work, Employment and Society 31(1):153-65. https://doi.org/10.1177/0950017016653087

Wirth, Heike and Andreas Fischer. 2008. "Die Umsetzung von ESeC fuer den kumulierten ALLBUS 1980-2006 (STATA-Routine, V4/4/2008)."

Wirth, Heike, Cornelia Gresch, Walter Müller, Reinhard Pollak, and Felix Weiss. 2010. "Measuring Social Class: The Case of Germany." Pp. 114-37 in Social Class in Europe : An Introduction to the European Socio-Economic Classification, edited by D. Rose and E. Harrison. London: Routledge.

Zou, Min. 2015. "Employment Relations and Social Stratification in Contemporary Urban China: Does Goldthorpe's Class Theory Still Work?" Sociology 49(6):1133-50.

https://doi.org/10.1177/0038038514562853 